\title{
Intrathecal baclofen for long-term treatment of spasticity: a multi-centre study
}

\author{
G OCHS, * A STRUPPLER,* B A MEYERSON, $\dagger$ B LINDEROTH, $\dagger$ J GYBELS,$\ddagger$ \\ B P GARDNER,§ P TEDDY,§ A JAMOUS,§ P WEINMANN\|
}

From the Departments of Neurology and Clinical Neurophysiology, ${ }^{*}$ Technische Universität, Munich, Federal Republic of Germany, the Department of Neurosurgery, $\uparrow$ Karolinska Hospital, Stockholm, Sweden, the Departments of Neurology and Neurosurgery, $\ddagger$ Katholieke Universiteit, Leuven, Belgium, the National Spinal Injuries Centre,§ Stoke Mandeville Hospital, Aylesbury, United Kingdom, and the Bakken Research Centre,\| Maastricht, Holland

SUMMARY Twenty eight patients with severe, intractable spasticity have been treated by chronic intrathecal administration of baclofen. An implantable programmable drug-administration-device (DAD) was used with a permanent intrathecal catheter. Infusion of 50 to $800 \mu \mathrm{g} / /$ day of baclofen completely abolished spasticity. Follow-up was up to two years. Therapeutic effect was documented by clinical assessment of tone, spasms and reflexes and by electrophysiological recordings of monoand polysynaptic reflex activity. Complications and untoward side-effects of the procedure were few. This procedure is recommended for spasticity of spinal origin refractory to physiotherapy and oral medication. It is a preferable alternative to ablative surgical intervention.

After an upper motoneuron lesion in man, a spastic syndrome often develops with a delay of weeks or months. This is characterised by hyperactive monoand polysynaptic reflexes and a velocity dependent increase in muscle tone. Depending on the site of the lesion, the features of the motor disorder can vary considerably. In spinal cord transection the powerful inhibitory action of the vestibulo-spinal pathway (projecting from the lateral vestibular nucleus) on the tonic innervation of flexors is eliminated, leading to an increase in flexor muscle tone of the legs. Lesions of the reticulo-spinal pathways cause loss of inhibition of the flexion reflex, resulting in spontaneous and sometimes painful flexor spasms. On the other hand, extensor spasms can also occur. All these patients suffer frequently from severe disability having their legs in a fixed, usually flexed, position causing nursing problems and severe handicap in daily life.

Flexor spasticity is often resistant to drugs in tolerable doses. Microsurgical procedures like selective peripheral neurotomy, posterior rhizotomy' and longitudinal myelotomy have been used. These interventions are designed to interrupt the spinal reflex arc or to reduce the afferent input to the dorsal horn.

Address for reprint requests: Dr Günter Ochs, Neurologische Klinik der Technischen Universität, Möhlstr. 28, D-8000 München 80, W Germany.

Received 20 July 1988 and in revised form 20 January 1989. Accepted 3 April 1989
Serious neurologic deficits such as bladder dysfunction, increasing paresis or sensory loss may occur and partial recurrence of the original symptoms are common. Therefore a non-destructive approach is preferable. In some cases spinal stimulation may provide a moderate amelioration of spasticity, particularly with regard to bladder function ${ }^{2}$ whereas cerebellar stimulation has proven to be ineffective in the long term. $^{3}$

Baclofen ( $\beta$-[4-chlorophenyl]-GABA, Lioresal), introduced as oral antispastic drug, is a gammaamino-butyric-acid (GABA)-anologue that selectively acts on the GABA-B-receptor. ${ }^{4}$ GABA itself is ineffective, because it does not penetrate the blood-brainbarrier in sufficient amounts. ${ }^{5}$ Its action on supraspinal and spinal cord synapses is inhibitory ${ }^{6}$ Baclofen is a lipophilic GABA mimetic drug. It primarily restricts calcium influx into the pre-synaptic terminal thereby reducing the pre-synaptic transmitter release. ${ }^{7}$ Evidence is accumulating for a postsynaptic action as well, ${ }^{6}$ depressing neuronal activity by an increase of potassium conductance. The reduction in muscle tone and possible anti-nociceptive ${ }^{8-11}$ effects are probably mediated by a stereospecific action on spinal interneurons, not via primary efferent neurons. The active enantiomer, L-baclofen, cannot be antagonised by Rbaclofen, ${ }^{1213}$ as suggested in previous studies. ${ }^{14}$

In about $25 \%$ of patients with spasticity due to spinal cord trauma or multiple sclerosis oral baclofen 
is ineffective. ${ }^{15}$ Combination with other antispastic drugs is often of little help. In high doses weakness, ataxia, drowsiness, insomnia, nausea, hypotension and psychosis may occur, particularly in response to sudden changes of dosage or withdrawal.

Epidural or intrathecal opioid administration is well established in pain therapy ${ }^{16} 17$ the major advantages being the low incidence of systemic side effects and the high analgesic effect. Epidural morphine has been shown to be effective also for spasticity, decreasing muscle tone as well as mono- and polysynaptic reflexes. ${ }^{18}$ Baclofen crosses the blood-brain-barrier poorly ${ }^{19}$ and is therefore an excellent candidate for intrathecal use. A major prerequisite for intrathecal use is non-toxicity to nervous tissue. In chronic animal studies no signs of toxic effects of intrathecal baclofen on the spinal cord were detected. ${ }^{20}$ In 1984 , intrathecal baclofen was first demonstrated to be effective in man. ${ }^{21}$ Bolus injections were initially employed and later on long-term treatment was performed by the use of implantable drug-administration-devices (DAD). ${ }^{22}$ Several other studies have subsequently been published. ${ }^{23}{ }^{24}$ Intrathecal baclofen seems to be effective also in tetanus. ${ }^{25}$

We present the results of a multi-centre study conducted at four independent hospitals in four European countries following identical investigational protocols and using the same, programmable DAD for intrathecal application of baclofen as treatment of spasticity.

\section{Materials and methods}

The study was performed using a prospective, open design. Strict records of adverse effects, patient related and other pertinent data were collected. Neurological status including degree of hypertonia, reflexes, spontaneous spasms and voluntary motor function were recorded. Many of the patients were video-recorded before and after treatment. The use of an investigational pump device, the drug and the protocol were approved by the local ethical committees. All patients and the nearest relatives, who were involved in the therapeutic decision, gave informed consent. Patients were free to withdraw from participation in the study at any time. Patient selection: All patients included in the study suffered from severe chronic para- or tetraspasticity with various aetiologies. Most of them were confined to wheelchair or bedridden, unable to walk and dependent on continuous nursing care. They were unresponsive to oral baclofen up to $100 \mathrm{mg} /$ day, as well as to alternative drugs (tizanidine, dantrolene, memantine and diazepam). All ancillary medications had been stabilised.

Most of the patients suffered from pain due to increased muscle tone or spontaneous spasms. Many of them also had severe paraplegic pain of a deafferentation type. Ablative surgery as mentioned above, had not been performed; however, one patient (no 11) had regularly used a dorsal cord stimulator (DCS) for three years. The underlying diseases, multiple sclerosis (12), spinal cord trauma (10), cervical myelopathy (2), hereditary spasticity (1), arachnoid cyst (1), myelitis (1) and intracerebral haemorrhage (1) were stable or extremely slow in progression. Patients with poor life expectancy, psychic disturbance, doubtful immunostability or otherwise physical debilitation were excluded from the study. Procedure: Prior to implantation CSF flow studies, generally a myelography, radiography of the spine and routine blood tests were performed. Intrathecal bolus injections were given to rule out adverse reactions and to ensure the therapeutic effect of the drug by this route of administration. The first bolus usually contained $25 \mu \mathrm{g}$ to $40 \mu \mathrm{g}$. When the effect on spasticity was insufficient a second or third bolus with doses varying between 80 and $120 \mu \mathrm{g}$ was given. A marked reduction of spasticity was observed in all patients tested.

Implantation: The implantation of the DAD was performed in one session. A 4F-"Silastic" catheter (Model 8701 or 8703), Medtronic Inc, Minneapolis, USA) was introduced through a Tuohy-needle under local anaesthesia between L3 and $\mathrm{L} 4$ and the tip pushed rostrally $10-15 \mathrm{~cm}$ in the subarachnoidal space, reaching at least the Th11/L1 level. The catheter placement was confirmed peroperatively by fluoroscopy or later by radiography. The catheter was sutured to the fascia and tunnelled subcutaneously to the lateral abdominal wall, where a subcutaneous pocket for the DAD was made. The DAD was sutured to the fascia and connected to the catheter.

The implantable pump (SynchroMed ${ }^{\mathrm{R}}$, Model $8611 \mathrm{H}$, Medtronic Inc, Minneapolis USA) contains a drug reservoir of $20 \mathrm{ml}$ volume, a lithium-thionyl-chloride battery powered peristaltic roller pump and an electronic circuit. Continuous infusion $(60 \mu \mathrm{g} / \mathrm{d}$ to $10.8 \mathrm{mg} / \mathrm{d})$, bolus or bolus-delay drug delivery can be programmed by means of a physician's microcomputer and can be transmitted to the implanted pump non-invasively via a hand-held radio-frequency telemetry wand. The filled device weighs $195 \mathrm{~g}$ (OD $7.5 \mathrm{~cm}$, thickness $2 \cdot 5 \mathrm{~cm}$ ).

Prior to implantation the device was filled with $10-12 \mathrm{ml}$ of the drug in a low concentration, usually $500 \mu \mathrm{g} / \mathrm{ml}$ (delivered by Ciba Geigy Corp, Basel, Switzerland). The flow was started shortly after implantation and the patient's individual need of dosage could usually be determined within 3 to 5 days postoperatively. Refills were performed by a percutaneous puncture through a rubber septum in the pump device with intervals ranging between 20 to 90 days, although even longer intervals would have been possible in some cases.

Since the implantation of a medical device in the human body carries an increased risk of infection, most patients received prophylactic antibiotics the day of the implantation (prior to surgery) and up to 3 days thereafter. The only pump pocket infection occurred in one of the first patients who did not receive prophylactic antibiotics.

Follow-up: The effect of treatment was quantified by clinical ratings, using the Ashworth-scale for muscle tone assessment and rating scales for frequency and severity of spontaneous spasms and strength of tendon reflexes. The patients were evaluated during the hospital stay and thereafter at monthly intervals, later every second month or at the time of refilling the pump. Re-programming with checking of pump function was performed on the same occasions.

Electrophysiological measurements: The spastic syndrome is the clinical manifestation of exaggerated mono- and polysynaptic spinal reflexes. Therefore, EMG recordings of 
motor responses were performed in a subgroup of the patients to quantify the therapeutic outcome. The effect of the drug on spinal function can be studied by assessing the inhibition of the flexion reflex - with its clinical feature of spontaneous or induced spasms-and the suppression of an exaggerated tendon reflex for example a sustained ankle clonus. Both reflexes were recorded from the corresponding muscles in the lower extremities, tibialis anterior, biceps femoris and soleus.

The flexion reflex was elicited semiquantitatively by mechanical stimulation at the lateral aspect of the foot. In this way a relatively physiologic stimulus was applied allowing spatial and temporal summation for the polysynaptic reflex. Wire electrodes were placed in the muscle belly to maintain stable recording conditions during movements of the leg. The ankle clonus was elicited manually by sudden dorsiflexion of the foot. The usual amplifier, filter and averager setup was used to obtain the EMG data. In a few patients muscle tone was assessed by measuring mechanical resistance to passive movement (tonography).

\section{Results}

Clinical experience: In total, 28 patients have been implanted. All have had considerable benefit from the procedure. Since most were unable to walk and were confined to wheelchair, their subjective assessment was concentrated on relief from painful and disturbing spasms, improvement of passive mobility, facilitation of nursing care and physical therapy. Many patients suffering from spontaneous spasms at night were able to sleep undisturbed and had considerably less problems in dressing and personal hygiene. In cases with spastic bladder disturbance voiding was facilitated (cf ref 25). Patients able to walk, that is, having minor degrees of paresis or using their spastic increase of extensor tone to maintain upright posture (patients nos. 9, 12, 21, 24), were difficult to titrate, because baclofen caused weakness. A careful titration of the daily dose was necessary to allow enough tone for standing or walking. Very low doses were generally needed (see table). Sometimes the pump had to be programmed for a bolus mode with higher doses during the evening and nights than during daytime. No patient able to walk prior to implantation deteriorated in this respect. In two patients not included in the study, a proper dose could not be titrated to maintain their walking capacity and at the same time obtain a useful reduction of spasticity. Some patients (no. 5, 9, 12) remained on low

Table List of patients included in the study

\begin{tabular}{|c|c|c|c|c|c|c|c|}
\hline \multirow[b]{2}{*}{ No } & \multirow[b]{2}{*}{ Diagnosis } & \multirow{2}{*}{$\begin{array}{l}\text { Age } \\
\text { (yr) }\end{array}$} & \multirow[b]{2}{*}{ Sex } & \multirow{2}{*}{$\begin{array}{l}\text { Duration of } \\
\text { disease }(y r) *\end{array}$} & \multirow{2}{*}{$\begin{array}{l}\text { Follow-up } \\
\text { (months) }\end{array}$} & \multicolumn{2}{|c|}{ Dose ( $\mu g /$ day $)$} \\
\hline & & & & & & Initial & Final \\
\hline \multirow{29}{*}{$\begin{array}{r}1 \\
2 \\
3 \\
4 \\
5 \\
6 \\
7 \\
8 \\
9 \\
10 \\
11 \\
12 \\
13 \\
14 \\
15 \\
16 \\
17 \\
18 \\
19 \\
20 \\
21 \\
22 \\
23 \\
24 \\
25 \\
26 \\
27 \\
28\end{array}$} & Multiple sclerosis & 59 & $\mathbf{F}$ & 11 & 25 & 72 & 195 \\
\hline & Multiple sclerosis & 46 & $\mathbf{F}$ & 18 & 24 & 240 & 380 \\
\hline & Multiple sclerosis & 26 & $\mathbf{F}$ & 6 & $21+$ & 260 & 84 \\
\hline & Trauma & 64 & $\mathbf{M}$ & 2 & 20 & 100 & 205 \\
\hline & Multiple sclerosis & 37 & $\mathbf{M}$ & 6 & 17 & 35 & 50 \\
\hline & Trauma & 33 & $\mathbf{M}$ & 1 & $13 \S$ & 620 & 780 \\
\hline & Multiple sclerosis & 61 & $\mathbf{F}$ & 23 & $13 \S$ & 95 & 84 \\
\hline & Multiple sclerosis & 51 & $\mathbf{M}$ & 16 & $12^{\circ}$ & 145 & 150 \\
\hline & Hereditary & 44 & $\mathbf{F}$ & 29 & $12 t$ & 32 & 32 \\
\hline & Trauma & 27 & $\mathbf{M}$ & 6 & $12^{+}$ & 70 & 130 \\
\hline & Cerv. sten. & 52 & $\mathbf{F}$ & 10 & 121 & 86 & 131 \\
\hline & Multiple sclerosis & 56 & $\mathbf{F}$ & 23 & $10 \ddagger$ & 26 & 48 \\
\hline & Trauma & 39 & $\mathbf{M}$ & 1 & $9^{+}$ & 360 & 500 \\
\hline & Trauma & 62 & $\mathrm{~F}$ & 1 & 9 & 100 & 250 \\
\hline & Trauma & 40 & $\mathbf{M}$ & 1 & 8 & 74 & 300 \\
\hline & Multiple sclerosis & 49 & $\mathbf{F}$ & 7 & 8 & 144 & 168 \\
\hline & Multiple sclerosis & 52 & $\mathrm{~F}$ & 13 & 7 & 165 & 335 \\
\hline & Multiple sclerosis & 55 & $\mathbf{F}$ & 14 & 7 & 215 & 263 \\
\hline & Trauma & 47 & $\mathbf{F}$ & 1 & 5 & 74 & 74 \\
\hline & Arachnoid cyst & 24 & $\mathbf{M}$ & 3 & 5 & 240 & 480 \\
\hline & Myelopathy & 47 & $\mathbf{M}$ & 1 & $4 t$ & 136 & 144 \\
\hline & Haemorrhage & 57 & $\mathbf{M}$ & 1 & 4 & 157 & 286 \\
\hline & Trauma & 63 & $\mathbf{M}$ & 38 & 3 & 86 & 86 \\
\hline & Trauma & 50 & $\mathbf{M}$ & 25 & $3 t$ & 35 & 35 \\
\hline & Multiple sclerosis & 44 & $\mathbf{F}$ & 14 & 3 & 55 & 55 \\
\hline & Trauma & 20 & $\mathbf{M}$ & 2 & 2 & 132 & 132 \\
\hline & Multiple sclerosis & 48 & $\mathbf{F}$ & 15 & 2 & 240 & 287 \\
\hline & Myelitis & 36 & $\mathbf{M}$ & 3 & 1 & 35 & 35 \\
\hline & Mean values (SD) & $46(1$ & & & 271 & $144 * *$ & $203^{* *}$ \\
\hline
\end{tabular}

*At time of implantation.

+Patient died from underlying disease.

tPatient is able to walk or at least to stand.

\&Pump replaced due to pump failure or infection.

|Since 1984 DCS with good effect; still using stimulator to supplement baclofen and minimise dose requirements.

$* * 143 \cdot 9,(125 \cdot 3)$ and $203 \cdot 5,(173 \cdot 5)$. 
concentrations or obtained a higher concentration of $1000 \mu \mathrm{g} / \mathrm{ml}$ depending on drug needs.

Muscle tone: The clinical score of muscle tone was rated according to the Ashworth scale by the physician and by the physiotherapist independently and averaged in case of diverging estimates. A dose dependent reduction or normalisation of tone was often achieved within the first few days. In some patients an irreversible muscle and tendon shortening had developed (contracture) as a result of the longstanding spastic tone increase. The ensuing reduction of movement span became more obvious when the muscle tone was normalised. Figure 1 presents the ratings and reflects the stability of therapy with followup up to two years.

Muscle tone, rated in terms of the Ashworth scale, is depicted versus time after implantation (fig 1A). Shortly after the implantation and onset of intrathecal therapy the average muscle tone was reduced from $3 \cdot 6$, SD 0.35 to $1 \cdot 75$, SD 0.31. It further decreases to almost normal values in the following months. In all patients physical therapy became more effective, wheelchair
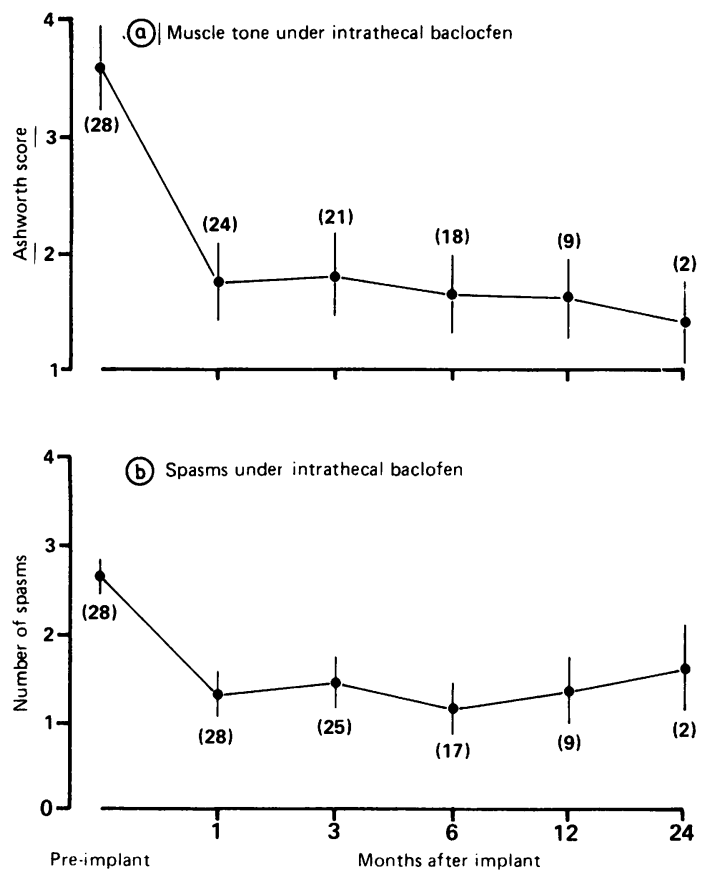

Fig 1 Changes in muscle tone $(A)$ and average number of spasms per hour $(B)$ under intrathecal baclofen during the 2 year follow-up. Quantification was done clinically by the Ashworth scale: 1 = normal muscle tone, 2 = small increase, $3=$ moderate increase, $4=$ massive increase, $5=$ joint fixed in flexed or extended position. Values are averaged from tone scores of different raters. Numbers in parentheses: number of patients. Vertical bars indicate standard deviation. The full line connects mean values. transportation or getting in/out of bed was greatly facilitated. Three patients were able to go back to work.

Spasms and reflexes: Figure 1B shows effects of intrathecal baclofen on the average number of spasms per hour versus time after implantation. Again a decrease of the number of spasms was observed; however, a slight increase occurred during the first year. This was the most frequent reason for dose increase in later stages of the therapy in some patients.

Most of the patients exhibited increased muscle spasms mainly in the evening or at night time. Effects on spasms developed later and with higher baclofen doses as compared with reduction on muscle tone. Spasms were markedly reduced in all cases. The muscle tone was usually flaccid or markedly reduced Those suffering from painful spasms due to an incomplete spinal lesion became free of pain. To avoid venous stasis in the legs, the drug was titrated to allow some spontaneous spasms. The reduction of spontaneous spasms developed in parallel with a decreased hypereflexic activity of the bladder, resulting in less frequent voiding. In a patient (no. 11) who had a DCS previously implanted for extremely severe extensor spasms it was found that stimulation and DAD baclofen infusion had additive effects. She used stimulation to inhibit temporary spells of spasms and to supplement the effects of baclofen the required dose of which could thus be minimised.

Changes in dosage: Once individual dose requirement were met and muscle tone was stabilised, the patiento were discharged from the ward. However, in $\vec{a}+$ considerable number of patients an increase of dose was necessary to maintain the initial therapeutic effect. This tendency to drug tolerance varied considerably as did the individual dose requirements (see table and fig 2). Usually the increase of dosage, to retain the therapeutic effect, became evident during the first 3 months. Dose increase varied between $5 \%$ and $500 \%$. Later on, stable conditions were reached in most cases. Some patients experienced an increasing number of spasms even after one year, often as the first sign of tolerance.

Electrophysiologic data: Recordings of flexion reflex and ankle clonus were performed in a subgroup of the patients prior to treatment, after bolus injection or during the stable phase of drug treatment. Rectified EMG recordings prior to treatment and with continuous infusion of baclofen $235 \mu \mathrm{g} /$ day are presented in fig 3. The EMG response (fig $3 \mathrm{~A}$ ), associated with a massive complex flexor spasm, shows a variable delay of about 1 second which typically accounts for the temporal and spatial summation of polysynaptic reflexes. With baclofen, no EMG response could be observed, which reflects the complete suppression of the GABA-ergic spinal interneuron activity. Similar 


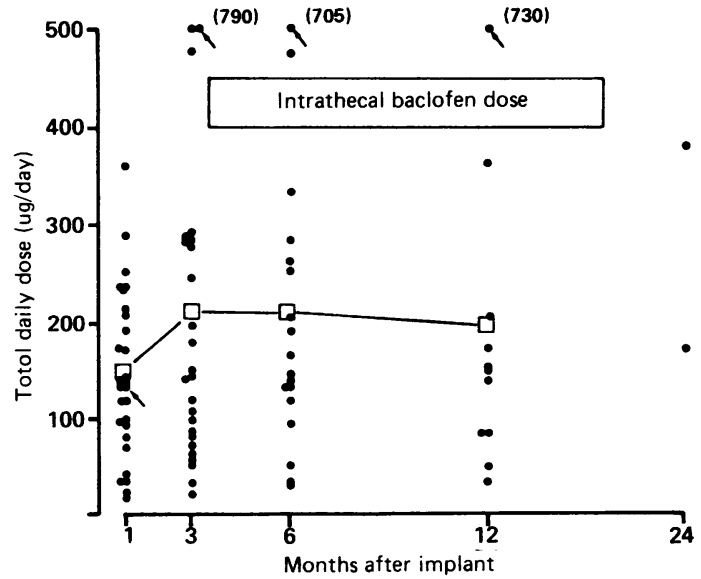

Fig 2 Changes in dose requirements during the follow-up. Dose increase during the first 3 months. Pat. no. 6 (indicated by arrow) showed significant tolerance to baclofen and was therefore switched to morphine every 3 months. Marked inter-individual differences of dose requirements. recordings could be made with morphine used epidurally for treatment of spasticity of spinal origin ${ }^{24}$ suggesting that encephalinergic interneurons are also involved in the same spinal circuit. Both GABA-ergic and encephalinergic binding sites are supposed to be located at the terminals of descending inhibitory pathways.

EMG recordings from the soleus muscle clearly demonstrated a powerful suppression also of monosynaptic reflex activity (fig 3B). After continuous baclofen infusion only one or two jerks of the ankle occurred, whereas prior to treatment sustained ankle clonus could be elicited. Both types of recordings illustrate the baclofen effect on disinhibited reflexes in spastic patients, independent of the actual locus of the lesion, either spinal or supraspinal.

Complications: All complications encountered in the patients were transient. They were related to technical problems with the pump device or the catheter, as well as to effects of the drug itself. One pump failure occurred after 3 months of normal functioning. It was

(a) Flexor reflex: $m$. tibialis ant. rectified EMG recordings

No drug

B. Baclofen $235 \mu \mathrm{g} /$ day intrathecal

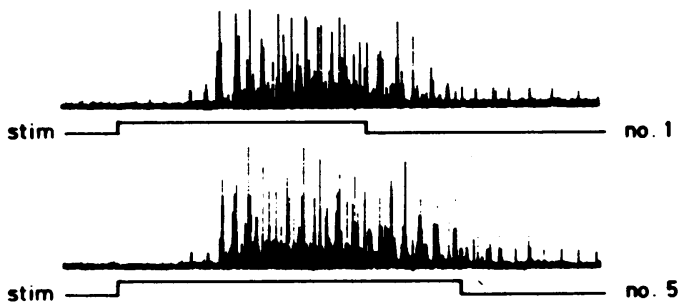

Average : 16 responses

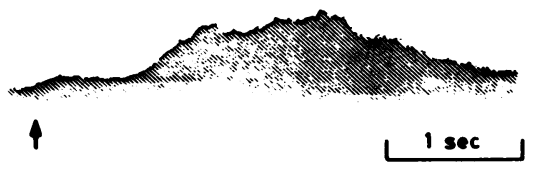

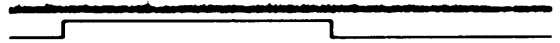

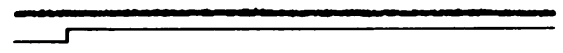

16 responses

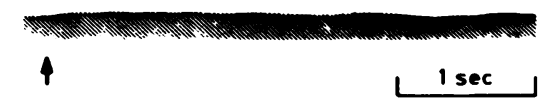

(b)

Ankle clonus $m$. soleus rect. EMG

No drug
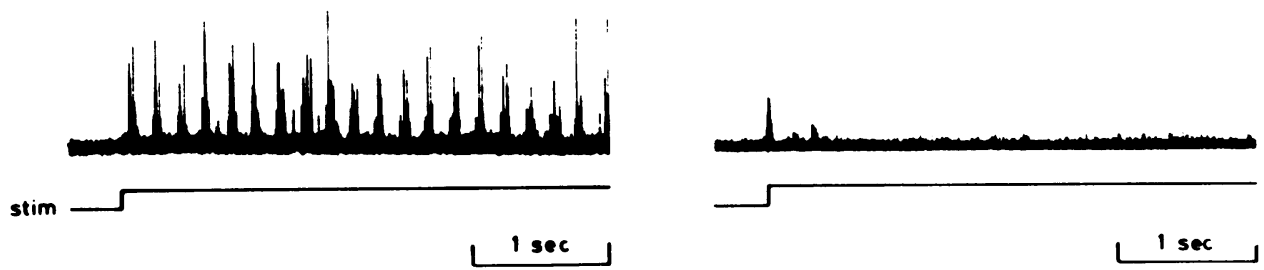

Fig 3 Rectified EMG recordings of flexor reflex ( $A$, upper panel) from the $m$. tibialis anterior and ankle clonus ( $B$, lower panel) prior to treatment and under continuous intrathecal baclofen $235 \mu \mathrm{g} /$ day (pat no 1). Mechanical stimulation. Averaged response at the bottom of $(A)$, arrows indicating time of stimulus onset. Flexor reflex and monosynaptic reflex response is abolished under therapy. 
caused by insufficient lubrication of the pump motor gear; this problem has been taken care of in later models and no more device failures occurred. The new device functioned satisfactorily for 12 months. Another pump had to be removed because of a pocket infection 3 days after implantation and replaced 2 months later; this patient has been doing well during the last 12 months. All other pumps worked without any problems.

In two patients the catheter had to be replaced owing to dislocation shortly after implantation. In subsequent cases this problem was overcome by advancing the catheter tip $10 \mathrm{~cm}$ more rostrally in the subarachoid space. One catheter, inserted under total anaesthesia, had to be replaced because it irritated a sacral root and caused radicular pain. The pain disappeared after correction of the catheter position. All subsequent operations were performed under spinal anaesthesia to avoid root irritation in the awake patient. In one patient the tip of the catheter was blocked after about 4 months and had to be exchanged.

Side effects of the drug: Unwanted side effects were rare and tolerable. Some patients complained of slight fatigue or sleepiness, mainly after the test bolus injection or in the beginning of the therapy. By slow, stepwise changes of the dose this problem could be avoided.

Some patients became more aware of their degree of paresis, when tone became reduced as a result of the treatment. Thus those patients who previously were able to walk as a result of an increased extensor tone, had trouble standing up. Also weakness in the upper extremities became apparent occasionally, in particular when the catheter was placed higher than at a mid-thoracic level. In particular, this often occurred in multiple sclerosis patients who also suffered from minor latent paresis or moderate spasticity in the arms.

In two patients concomitant self-medication, while on continuous intrathecal baclofen, caused reversible coma and respiratory depression making admission to the intensive-care unit necessary. Patient no. 3, already suffering from severe brainstem lesions due to multiple sclerosis with bulbar signs and occasional respiratory irregularities, had to be intubated because of respiratory depression. It was not known whether she had taken 80 or even $100 \mathrm{mg}$ of baclofen by mouth or sleeping pills in addition. Furthermore, a deterioration of the underlying disease (multiple sclerosis) might have contributed. She woke up within 36 hours and returned to a normal state. Patient no. 21, suffering from terminal renal insufficiency took $60 \mathrm{mg} /$ day of oral baclofen and became comatose. He was back to normal within 36 hours, followed by a baclofen withdrawal-induced psychosis. Concomitant oral medication should therefore be discontinued or carefully controlled by the physician.

Tolerance: Tolerance to baclofen was not a serious problem. Only in patient no. 4 was a $500 \%$ increase of the dose necessary. After about four months the patient again complained of progressive spontaneous painful spasms. Since opioids are known to be effective for spasticity (and pain), ${ }^{1826} 2.5-3.5 \mathrm{mg}$ /day morphine were administered by the drug pump instead of baclofen. There was good relief of spasticity for the following 1 to 2 weeks, but then signs of tolerance to this drug also became apparent. Baclofen was therefore again instituted and proved to be effective.

\section{Discussion}

It must be emphasised that only the pain due to the muscle spasms could be influenced by the baclofen treatment. The deafferentation pain remained completely unaffected corresponding to the completely different pathophysiology of this pain type.

Tolerance: One reason why an excessively high dose of baclofen was required in this particular patient might be due to the fact that the CSF circulation was hindered by a block at the site of the traumatic spinal cord compression not allowing redistribution in CSF. Thus the effect was mediated only by pure physical diffusion of the compound. As a rule, intrathecal baclofen is not recommended when abnormal CSFO circulation is present.

Overdose: Since no pharmacological antagonist iso available for baclofen to date, the problem of overdose is of major importance. Recently the cholinergic compound physostigmine has been shown to have antagonistic properties in case of overdose. In animal experiments physostigmine $0.1 \mathrm{mg} / \mathrm{kg}$ i.v. maintained respiratory rate when given at 30 minute intervals to dogs that had received $50-400 \mu \mathrm{g}$ of baclofen intracisternally. ${ }^{27}$ In three patients who suffered from respiratory depression after an accidental bolus injection of 80-800 $\mu \mathrm{g}$ baclofen intrathecally, $2 \mathrm{mg}$ of physostigmine i.v. reversed the respiratory depression and somnolence within minutes. In one case a second injection of $2 \mathrm{mg}$ was necessary. ${ }^{28}$ In animal experiments high doses of baclofen directly depress medullary inspiratory neurons, whereas low doses increase respiratory activity by disinhibition of medullary neurons.

Since the rostral spread of the drug presumably is insufficient, it may be hypothesised that the cerebral GABA-receptors are very sensitive in patients who are on intrathecal baclofen. The oral doses used prior to implantation are therefore often too high, resulting in serious overdose problems in case of uncontrolled intake.

Follow-up requirements: Patients should be carefully 
followed after implantation for adjusting the dose, monitoring the DAD's proper operation, management of complications or side effects. Unfortunately, there is at present no way by which the patient himself can stop the pump. It can only be stopped with the physician's programming computer at the hospital. The method should therefore be restricted to medical centres offering a 24-hour-emergency-service, at least at this early stage of experience. Furthermore, regular refill requirements set limits as to the distance to the service centre.

Despite some obvious risks and difficulties, this new technique offers many benefits. Intrathecal baclofen infusion with an implantable DAD seems at present to be the most effective way to treat severe spasticity in patients in a stable disease stage. It may be more expensive than alternative neurosurgical procedures commonly used but carries much less risk of complications. Furthermore, spinal baclofen infusion is currently the early stage of a new era of local drug administration to the hypothetical site of drug action.

\section{References}

I Sindou M, Abdennebi N, Sharkey P. Microsurgical selective procedures in peripheral nerves and the posterior root-spinal cord junction for spasticity. Appl Neurophysiol 1985;48: 97-104.

2 Gybels J, van Roost D. Spinal cord stimulation for spasticity. In: Symon et al. Advances and technical standards in neurosurgery, Vol 15. Wien, New York: Springer, 1987:63-96.

3 McLellan DL, Selwyn M, Cooper IS. Time course of clinical and physiological effects of stimulation of the cerebellar surface in patients with spasticity. J Neurol Neurosurg Psychiatry 1978;41:150-60.

4 Bowery NG, Hill DR, Hudson AL. 3H-GABA and 3H-baclofen are ligands for the same bicuculline-insensitive site on mammalian CNS synaptic membranes. Proc of the BPS, April 1981, 222P-223P.

5 Faigle JW, Keberle H. Metabolismus und pharmakokinetik von lioresal. In: Birkmayer W, ed. Aspekte der muskelspastik. Bern: Verlag Hans Huber, 1972:94-100.

6 Zieglgänsberger W, Howe JR, Sutor B. The Neuropharmacology of Baclofen. In: Müller $\mathbf{H}$, et al, eds. Local-spinal Therapy of Spasticity. Heidelberg: Springer, 1988:37-49.

7 Davidoff RA. Antispastic Drugs. Mechanisms of Action. Ann Neurol 1985; 17:107-16.
8 Henry JL. Effects of Intravenously Administered Enantiomers of Baclofen on the Functionally Identified Units in Lumbar Dorsal Horn of the Spinal Cat. Neuropharmacology 1982;21:1073-83.

9 Wilson PR, Yaksh TL. Baclofen is Antinociceptive in the Spinal Intrathecal Space of Animals. Eur J Pharmacol 1978;51:323-30.

10 Fromm GH, Terrence CF, Chattha AS. Baclofen in the Treatment of Trigeminal Neuralgia: Double-Blind Study and Long-Term Follow-up. Ann Neurol 1984;15:240-4.

11 Steardo L, Leo A, Marano E. Efficacy of Baclofen in Trigeminal Neuralgia and some Other Painful Conditions. Eur Neurol 1984;23:51-5.

12 Haas HL, Greene RW, Olpe HR. Stereoselectivity of L-Baclofen in Hippocampal Slices of the Rat. Neurosci Lett 1985;55:1-4.

13 Howe JR, Zieglgänsberger W. D-Baclofen does not antagonize the Actions of L-Baclofen on Rat neocortical Neurons in vitro. Neurosci Lett 1986;72:99-104.

14 Sawynok J, Dickson C. D-Baclofen is an Antagonist at Baclofen Receptors. Mediating Antinociception in the Spinal Cord. Pharmacology 1985;31:248-59.

15 Jones RF, Burke D, Marosszeky JE, Gillies JD. A New Agent for the control of spasticity. J Neurol Neurosurg Psychiatry 1970;33:464-8.

16 Penn RD, Paice JA. Chronic intrathecal morphine for intractable pain. J Neurosurgery 1987;67:182-6.

17 Rawal N, Arner S, Gustafsson LL, Allvin R. Present state of extradural and intrathecal opioid analgesia in Sweden. A nationwide follow-up survey. Br J Anaesth 1987;59:791-9.

18 Struppler A, Burgmayer B, Ochs G, Pfeiffer HG. The effect of epidural application of opioids on spasticity of spinal origin. Life Sci 1983;33 (suppl 1):607-10.

19 Knutsson E, Lindblom U, Martensson A. Plasma and cerebrospinal fluid levels of baclofen (Lioresal) at optimal therapeutic responses in spastic paresis. J Neurol Sci 1974;23:473-84.

20 Kroin JS, Penn RD, Bessinger RL, Arzbaecher RC. Reduced Spinal Reflexes Following Intrathecal Baclofen in the Rabbit. Exp Brain Res 1984;54:191-4.

21 Penn RD, Kroin JS. Intrathecal Baclofen alleviates spinal cord spasticity. Lancet 1984;i:1078.

22 Penn RD, Kroin JS. Continuous intrathecal Baclofen for severe Spasticity. Lancet 1985;ii:125-7.

23 Müller H, Zierski J, Dralle D, Börner U, Hoffmann O. The effect of intrathecal baclofen on electrical muscle activity in spasticity. J Neurol 1987;234:348-52.

24 Ochs G, Struppler A. Treatment of Spasticity by Implantable Drug Administration Devices and Intrathecal Catheter. In: Benecke R, Conrad B, Marsden CD, eds. Motor Disturbances I. London: Academic Press, 1987:197-208.

25 Müller H, Börner U, Zierski J, Hempelmann G. Intrathecal Baclofen in Tetanus. Lancet 1986;iii:317-8.

26 Pedersen E, Petersen T, Schroeder HD. Relation between flexor spasms, uninhibited detrusor Contractions and anal Sphincter Activity. J Neurol Neurosurg Psychiatry 1986;49:273-7.

27 Müller-Schwefe G. Physostigmine reversal of Baclofen-induced sedation. In: Müller $\mathrm{H}$, et al, eds. Local-spinal therapy of spasticity. Heidelberg: Springer, 1988:253. 